\title{
Unified Synthesis of $\mathrm{C}_{19}-\mathrm{C}_{26}$ Subunits of Amphidinolides $B_{1}, B_{2}$ and $B_{3}$ by Exploiting Unexpected Stereochemical Differences in Crimmins' and Evans' Aldol Reactions.
}

\author{
Wei Zhang, Rich G. Carter* and Alexandre F. T. Yokochi ${ }^{\dagger}$ \\ Department of Chemistry, Oregon State University, Corvallis, OR 97331.
}

Electronic Supplementary Information

${ }^{\dagger}$ Director of X-ray Crystallographic Facility, Department of Chemistry, Oregon State University, Corvallis, OR 97331, E-mail: Alexandre.Yokochi@oregonstate.edu. 
General. Infrared spectra were recorded neat unless otherwise indicated. ${ }^{1} \mathrm{H}$ NMR spectra were recorded in $\mathrm{CDCl}_{3}$ and are reported in ppm relative to trimethylsilane and referenced internally to the residually protonated solvent. ${ }^{13} \mathrm{C}$ NMR spectra were recorded in $\mathrm{CDCl}_{3}$ and are reported in ppm relative to trimethylsilane and referenced internally to the residually protonated solvent. Optical rotations were recorded using a sodium lamp at $589 \mathrm{~nm}$ in $\mathrm{CHCl}_{3}$.

Routine monitoring of reactions was performed using EM Science DC-Alufolien silica gel, aluminum-backed TLC plates. Flash chromatography was performed with the indicated eluents on EM Science Gedurian 230-400 mesh silica gel.

Air and / or moisture sensitive reactions were performed under usual inert atmosphere conditions. Reactions requiring anhydrous conditions were performed under a blanket of argon, in glassware dried in an oven at $120^{\circ} \mathrm{C}$ or by a bunsen flame, then cooled under argon. Solvents and commercial reagents were purified in accord with Perrin and Armarego ${ }^{1}$ or used without further purification.

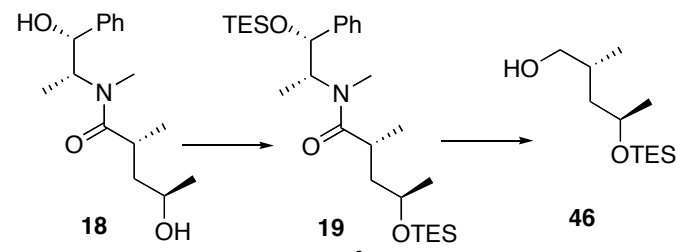

Silyl Ether 19: To a solution of diol $\mathbf{1 8}^{2}(215 \mathrm{mg}, 0.77 \mathrm{mmol})$ in $\mathrm{CH}_{2} \mathrm{Cl}_{2}$ at $0^{\circ} \mathrm{C}$ added sequentially $\mathrm{Et}_{3} \mathrm{~N}(0.32 \mathrm{~mL}, 2.32 \mathrm{mmol})$, DMAP $(28 \mathrm{mg}, 0.23 \mathrm{mmol})$ and TESCl $(0.29 \mathrm{~mL}, 1.93 \mathrm{mmol})$. After $2 \mathrm{~h}$, the reaction was quenched with sat. aq. $\mathrm{NH}_{4} \mathrm{Cl}(5 \mathrm{~mL})$ and extracted with $\mathrm{Et}_{2} \mathrm{O}(3 \mathrm{X} 10 \mathrm{~mL})$. The dried $\left(\mathrm{MgSO}_{4}\right)$ extract was concentrated in vacuo to give crude $19(0.77 \mathrm{mmol})$ and was used without further purification.

Alcohol 46: To a solution of diisopropyl amine $(0.45 \mathrm{~mL}, 3.2 \mathrm{mmol})$ in THF $(1.9 \mathrm{~mL})$ at $-78^{\circ} \mathrm{C}$ was added $n$ - $\mathrm{BuLi}\left(1.28 \mathrm{~mL}, 3.2 \mathrm{mmol}, 2.5 \mathrm{M}\right.$ in hexanes). After $10 \mathrm{~min}$, the solution was warmed to $0^{\circ} \mathrm{C}$. After $15 \mathrm{~min}, \mathrm{BH}_{3} \bullet \mathrm{NH}_{3}(110 \mathrm{mg}, 3.2 \mathrm{mmol})$ was added in one portion. The mixture was allowed to stir 15 min followed by warming to r.t. ( $15 \mathrm{~min})$ and recooling back to $0^{\circ} \mathrm{C}$. A solution of crude $19(0.77 \mathrm{mmol})$ in THF $(2.5 \mathrm{~mL})$ was added dropwise via syringe. After $2 \mathrm{~h}$, the reaction was warmed to r.t. After $10 \mathrm{~h}$, the reaction was quenched with sat. aq. $\mathrm{NH}_{4} \mathrm{Cl}(10 \mathrm{~mL})$ carefully and stirred $20 \mathrm{~min}$ until two heterogeneous layers formed. The mixture was extracted with $\mathrm{Et}_{2} \mathrm{O}(3 \mathrm{X} 10 \mathrm{~mL})$. The dried $\left(\mathrm{MgSO}_{4}\right)$ extract was concentrated in vacuo and purified by chromatography over silica gel, eluting with $10 \%$ EtOAc / hexanes, to give alcohol $46(140 \mathrm{mg}, 0.6 \mathrm{mmol}, 78 \%)$ as a colorless oil: $[\alpha]_{\mathrm{D}}{ }^{23}-9.3^{\circ}(\mathrm{c} 0.87)$; IR $3354(\mathrm{br}), 2956$, 2877, 1459, 1415, 1378, 1238, 1132, 1070, 1042, 1016, $744 \mathrm{~cm}^{-1}$; ${ }^{1} \mathrm{H}$ NMR (300 MHz) 8 4.01-4.07 (m, $1 \mathrm{H}), 3.44-3.48(\mathrm{~m}, 1 \mathrm{H}), 3.36-3.40(\mathrm{~m}, 1 \mathrm{H}), 3.21-3.26(\mathrm{~m}, 1 \mathrm{H}), 1.89-1.90(\mathrm{~m}, 1 \mathrm{H}), 1.47-1.51(\mathrm{~m}, 2 \mathrm{H}), 1.20$ $(\mathrm{d}, \mathrm{J}=6.3 \mathrm{~Hz}, 3 \mathrm{H}), 0.97(\mathrm{t}, \mathrm{J}=8.1 \mathrm{~Hz}, 9 \mathrm{H}), 0.88(\mathrm{~d}, \mathrm{~J}=6.9 \mathrm{~Hz}, 3 \mathrm{H}), 0.62(\mathrm{q}, \mathrm{J}=8.1 \mathrm{~Hz}, 6 \mathrm{H}) ;{ }^{13} \mathrm{C} \mathrm{NMR}$ $(75 \mathrm{MHz}) \delta 69.0,67.5,44.8,32.3,23.1,18.6,7.2,5.2$; HRMS (FAB+) calcd. for $\mathrm{C}_{12} \mathrm{H}_{29} \mathrm{O}_{2} \mathrm{Si}(\mathrm{M}+1)$ 233.1937 , found 233.1944 .

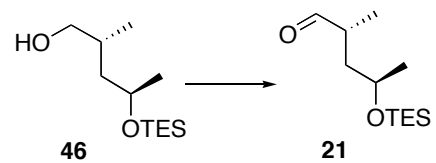

Aldehyde 21: To a solution of alcohol $46(170 \mathrm{mg}, 0.73 \mathrm{mmol})$ in $\mathrm{CH}_{2} \mathrm{Cl}_{2}(7.3 \mathrm{~mL})$ was added sequentially $4 \AA$ mol. sieves $(0.4 \mathrm{~g})$, NMO (129 mg, $1.1 \mathrm{mmol})$ and TPAP $(13 \mathrm{mg}, 0.036 \mathrm{mmol})$. After 30 min, the mixture was filtrated through a plug of $\mathrm{SiO}_{2}$ eluting with $30 \% \mathrm{Et}_{2} \mathrm{O} /$ pentane $(150 \mathrm{~mL})$. The solution was concentrated in vacuo to give the aldehyde $21(143 \mathrm{mg}, 0.62 \mathrm{mmol}, 85 \%)$ as a colorless oil: $[\alpha]_{\mathrm{D}}{ }^{23}-27.0^{\circ}$ (c 0.47); IR 2956, 2936. 2911, 2877, 1727, 1458, 1374, 1114, 1051, 1007, $743 \mathrm{~cm}^{-1}$; ${ }^{1} \mathrm{H}$ NMR $(300 \mathrm{MHz}) \delta 9.62(\mathrm{~d}, \mathrm{~J}=1.8 \mathrm{~Hz}, 1 \mathrm{H}), 3.91-3.97(\mathrm{~m}, 1 \mathrm{H}), 2.50-2.53(\mathrm{~m}, 1 \mathrm{H}), 1.78-1.87(\mathrm{~m}, 1 \mathrm{H}), 1.50-1.59$ $(\mathrm{m}, 1 \mathrm{H}), 1.18(\mathrm{~d}, \mathrm{~J}=4.8 \mathrm{~Hz}, 3 \mathrm{H}), 1.09(\mathrm{~d}, \mathrm{~J}=6.9 \mathrm{~Hz}, 3 \mathrm{H}), 0.93(\mathrm{t}, \mathrm{J}=7.5 \mathrm{~Hz}, 9 \mathrm{H}), 0.58(\mathrm{q}, \mathrm{J}=7.5 \mathrm{~Hz}$, 
$6 \mathrm{H}) ;{ }^{13} \mathrm{C}$ NMR $(75 \mathrm{MHz}) \delta 205.1,66.5,43.3,41.3,24.3,14.4,7.2,5.3$; HRMS (FAB+) calcd. for $\mathrm{C}_{12} \mathrm{H}_{26} \mathrm{O}_{2} \mathrm{Si}(\mathrm{M}+)$ 230.1702, found 230.1687.

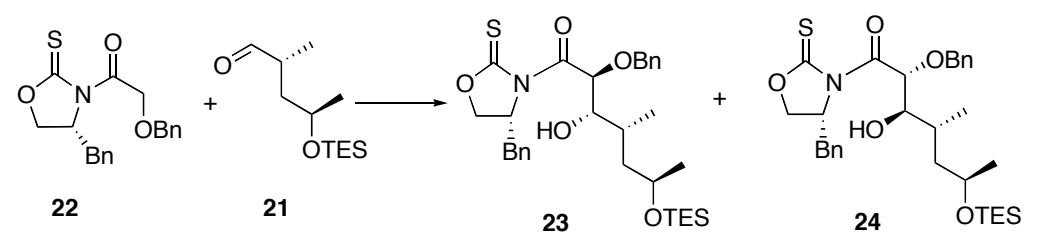

Aldol Adducts 23 and 24: To a solution of $\mathbf{2 2}^{3}(170 \mathrm{mg}, 0.50 \mathrm{mmol})$ in $\mathrm{CH}_{2} \mathrm{Cl}_{2}(1.5 \mathrm{~mL})$ at $-78^{\circ} \mathrm{C}$ added freshly distilled $\mathrm{TiCl}_{4}(0.055 \mathrm{~mL}, 0.50 \mathrm{mmol})$, followed with a solution of (-)-sparteine $(0.29 \mathrm{~mL}$, $0.125 \mathrm{mmol})$ in $\mathrm{CH}_{2} \mathrm{Cl}_{2}(0.5 \mathrm{~mL})$ dropwise. After $1.5 \mathrm{~h}$, a solution of the aldehyde $21(57 \mathrm{mg}, 0.25 \mathrm{mmol})$ in $\mathrm{CH}_{2} \mathrm{Cl}_{2}(0.5 \mathrm{~mL})$ was added dropwise to the solution via cannula. After $40 \mathrm{~min}$, the reaction was quenched at $-78^{\circ} \mathrm{C}$ with sat. aq. $\mathrm{NH}_{4} \mathrm{Cl}(5 \mathrm{~mL})$ and warmed to r.t. After $10 \mathrm{~min}$, the solution was extracted with $\mathrm{Et}_{2} \mathrm{O}(3 \mathrm{X} 10 \mathrm{~mL})$. The dried $\left(\mathrm{MgSO}_{4}\right)$ extract was concentrated in vacuo and purified by chromatography over silica gel, eluting with 10-15\% EtOAc / hexanes, to give 23 (63 mg, $0.11 \mathrm{mmol}$, $44 \%$ ) and 24 (42 mg, $0.07 \mathrm{mmol}, 30 \%)$ both isolated as colorless oil. 23: $[\alpha]_{\mathrm{D}}{ }^{23}-103.8^{\circ}$ (c 3.7); IR 3444, 3029, 2959, 2911, 2875, 1709, 1497, 1455, 1367, 1322, 1197, 1161, 1063, $747 \mathrm{~cm}^{-1} ;{ }^{1} \mathrm{H}$ NMR (300 MHz) ठ 7.18-7.37 (m, 10H), $6.25(\mathrm{~d}, \mathrm{~J}=9.3 \mathrm{~Hz}, 1 \mathrm{H}), 4.67(\mathrm{~d}, \mathrm{~J}=12.0 \mathrm{~Hz}, 1 \mathrm{H}), 4.52-4.61(\mathrm{~m}, 1 \mathrm{H}), 4.46(\mathrm{~d}, \mathrm{~J}=$ $11.7 \mathrm{~Hz}, 1 \mathrm{H}), 4.22(\mathrm{dd}, \mathrm{J}=1.8,9.0 \mathrm{~Hz}, 1 \mathrm{H}), 3.93-4.04(\mathrm{~m}, 3 \mathrm{H}), 3.18(\mathrm{dd}, \mathrm{J}=3.3,13.8 \mathrm{~Hz}, 1 \mathrm{H}), 2.94(\mathrm{~d}, \mathrm{~J}=$ $10.2 \mathrm{~Hz}, 1 \mathrm{H}), 2.73(\mathrm{dd}, \mathrm{J}=9.6,13.5 \mathrm{~Hz}, 1 \mathrm{H}), 2.18(\mathrm{ddd}, \mathrm{J}=2.1,6.9,8.7 \mathrm{~Hz}, 1 \mathrm{H}), 1.58-1.68(\mathrm{~m}, 1 \mathrm{H}), 1.48-$ $1.57(\mathrm{~m}, 1 \mathrm{H}), 1.18(\mathrm{~d}, \mathrm{~J}=6.0 \mathrm{~Hz}, 3 \mathrm{H}), 0.97(\mathrm{~d}, \mathrm{~J}=6.8 \mathrm{~Hz}, 3 \mathrm{H}), 0.96(\mathrm{t}, \mathrm{J}=7.8 \mathrm{~Hz}, 9 \mathrm{H}), 0.61(\mathrm{q}, \mathrm{J}=7.5 \mathrm{~Hz}$, $6 \mathrm{H}) ;{ }^{13} \mathrm{C}$ NMR (100 MHz) $\delta 186.8,175.4,137.5,135.4,129.9,129.7,129.4,128.71,128.67,127.8,77.3$, 75.3, 73.9, 71.2, 67.2, 60.7, 44.0, 37.6, 31.6, 24.2, 13.8, 7.4, 5.4; HRMS (FAB+) calcd. for $\mathrm{C}_{31} \mathrm{H}_{46} \mathrm{NO}_{5} \mathrm{SSi}$ $(\mathrm{M}+1) 572.2866$, found 572.2861 .

24: $[\alpha]_{\mathrm{D}}{ }^{23}-44.0^{\circ}$ (c 1.8); IR 3484, 3029, 2957, 2932, 2876, 1702, 1497, 1455, 1364, 1325, 1197 , 1160, 1061, $744 \mathrm{~cm}^{-1}$; ${ }^{1} \mathrm{H}$ NMR (300 MHz) $\delta 7.21-7.40(\mathrm{~m}, 10 \mathrm{H}), 6.59(\mathrm{~d}, \mathrm{~J}=8.4 \mathrm{~Hz}, 1 \mathrm{H}), 4.86-4.92(\mathrm{~m}$, $1 \mathrm{H}), 4.62(\mathrm{~s}, 2 \mathrm{H}), 4.20-4.31(\mathrm{~m}, 2 \mathrm{H}), 3.95(\mathrm{dt}, \mathrm{J}=6.3,18.3 \mathrm{~Hz}, 1 \mathrm{H}), 3.64(\mathrm{~s}, \mathrm{br} 1 \mathrm{H}), 3.54(\mathrm{~s}, \mathrm{br}, 1 \mathrm{H}), 3.18$ $(\mathrm{dd}, \mathrm{J}=3.3,13.2 \mathrm{~Hz}, 1 \mathrm{H}), 2.65(\mathrm{dd}, \mathrm{J}=10.5,13.5 \mathrm{~Hz}, 1 \mathrm{H}), 2.15-2.19(\mathrm{~m}, 1 \mathrm{H}), 1.54-1.64(\mathrm{~m}, 2 \mathrm{H}), 1.17(\mathrm{~d}$, $\mathrm{J}=6.3 \mathrm{~Hz}, 3 \mathrm{H}), 1.05(\mathrm{~d}, \mathrm{~J}=6.9 \mathrm{~Hz}, 3 \mathrm{H}), 0.94(\mathrm{t}, \mathrm{J}=7.8 \mathrm{~Hz}, 9 \mathrm{H}), 0.61(\mathrm{q}, \mathrm{J}=7.5 \mathrm{~Hz}, 6 \mathrm{H}) ;{ }^{13} \mathrm{C}$ NMR $(100$ $\mathrm{MHz}) \delta 186.8,175.5,137.7,135.8,129.8,129.4,129.0,128.8,128.5,127.8,78.8,77.6,73.2,71.2$, 67.1, 61.3, 41.0, 38.2, 33.3, 24.0, 17.4, 7.3, 5.3; HRMS (FAB+) calcd. for $\mathrm{C}_{31} \mathrm{H}_{46} \mathrm{NO}_{5} \mathrm{SSi}(\mathrm{M}+1)$ 572.2866, found 572.2871 .

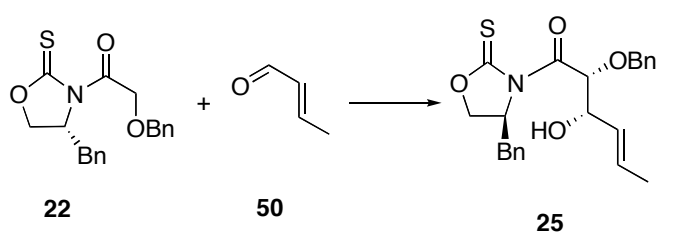

Aldol Adduct 25: To a solution of auxiliary $22(34 \mathrm{mg}, 0.10 \mathrm{mmol})$ in $\mathrm{CH}_{2} \mathrm{Cl}_{2}(0.6 \mathrm{~mL})$ at $-78^{\circ} \mathrm{C}$ added $\mathrm{TiCl}_{4}(0.011 \mathrm{~mL}, 0.1 \mathrm{mmol})$, and followed with (-)-sparteine $(0.060 \mathrm{~mL}, 0.25 \mathrm{mmol})$. After $1.5 \mathrm{~h}$, freshly distilled crotonaldehyde (50) $(13 \mu \mathrm{L}, 0.15 \mathrm{mmol})$ was added to the dark red solution dropwise. After $30 \mathrm{~min}$, the reaction was quenched at $-78^{\circ} \mathrm{C}$ with sat. aq. $\mathrm{NH}_{4} \mathrm{Cl}(5 \mathrm{~mL})$, allowed to warm to r.t. and extracted with $\mathrm{Et}_{2} \mathrm{O}(3 \mathrm{X} 10 \mathrm{~mL})$. The dried $\left(\mathrm{MgSO}_{4}\right)$ extract was concentrated in vacuo and purified by chromatography over silica gel, eluting with 20-40\% EtOAc / hexanes, to give major product $\mathbf{2 5}$ (33 mg, $0.08 \mathrm{mmol}, 80 \%$ ) as a white solid: $[\alpha]_{\mathrm{D}}{ }^{23}+1.4^{\circ}$ (c 0.97); IR 3446, 3032, 2923, 2854, 1706, 1496, 1454, 1364, 1326, 1197, 1161, 965, $740 \mathrm{~cm}^{-1}$; ${ }^{1} \mathrm{H}$ NMR $(300 \mathrm{MHz}) \delta 7.20-7.33(\mathrm{~m}, 10 \mathrm{H}), 6.26(\mathrm{~d}, \mathrm{~J}=3.3 \mathrm{~Hz}$, $1 \mathrm{H}), 5.71-5.81(\mathrm{~m}, 1 \mathrm{H}), 5.58-5.65(\mathrm{~m}, 1 \mathrm{H}), 4.80-4.87(\mathrm{~m}, 1 \mathrm{H}), 4.75(\mathrm{~d}, \mathrm{~J}=11.4 \mathrm{~Hz}, 1 \mathrm{H}), 4.62(\mathrm{~d}, \mathrm{~J}=11.4$ $\mathrm{Hz}, 1 \mathrm{H}), 4.48(\mathrm{~s}, \mathrm{br}, 1 \mathrm{H}), 4.24-4.35(\mathrm{~m}, 2 \mathrm{H}), 3.24(\mathrm{dd}, \mathrm{J}=3.3,13.2 \mathrm{~Hz}, 1 \mathrm{H}), 2.72(\mathrm{dd}, \mathrm{J}=3.3,13.6 \mathrm{~Hz}$, 1H), $2.52(\mathrm{~d}, \mathrm{~J}=6.6 \mathrm{~Hz}, 1 \mathrm{H}), 1.70(\mathrm{~d}, \mathrm{~J}=6.9 \mathrm{~Hz}, 3 \mathrm{H}) ;{ }^{13} \mathrm{C} \mathrm{NMR}(100 \mathrm{MHz}) \delta 185.6,172.0,137.4,135.5$, 
129.9, 129.5, 129.0, 128.9, 128.7, 127.9, 80.0, 74.1, 73.8, 71.3, 61.3, 37.9, 18.2; HRMS (FAB+) calcd. for $\mathrm{C}_{23} \mathrm{H}_{26} \mathrm{NO}_{4} \mathrm{~S}(\mathrm{M}+1)$ 412.1583, found 412.1589 .

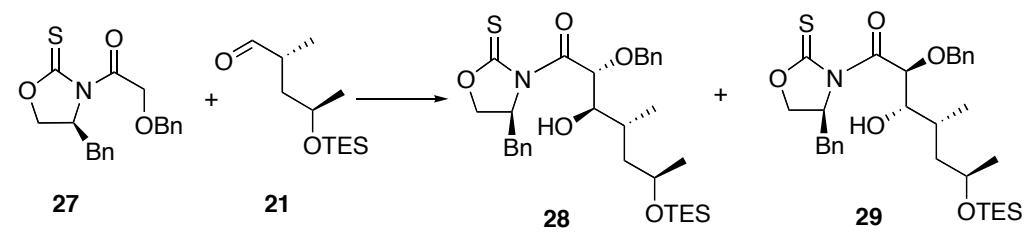

Aldol Adducts 28 and 29: To a solution of $\mathbf{2 7}$ (230 mg, $0.673 \mathrm{mmol})$ in $\mathrm{CH}_{2} \mathrm{Cl}_{2}(3.3 \mathrm{~mL})$ at $-78^{\circ} \mathrm{C}$ added freshly distilled $\mathrm{TiCl}_{4}(0.074 \mathrm{~mL}, 0.673 \mathrm{mmol})$, followed with a solution of (-)-sparteine $(0.15$ $\mathrm{mL}, 0.673 \mathrm{mmol})$ in $\mathrm{CH}_{2} \mathrm{Cl}_{2}(0.7 \mathrm{~mL})$ dropwise. After $1.5 \mathrm{~h}$, a solution of aldehyde 21 (98 $\left.\mathrm{mg}, 0.43 \mathrm{mmol}\right)$ in $\mathrm{CH}_{2} \mathrm{Cl}_{2}(0.5 \mathrm{~mL})$ was added dropwise to the solution via cannula. After $40 \mathrm{~min}$, the reaction was quenched at $-78^{\circ} \mathrm{C}$ with sat. aq. $\mathrm{NH}_{4} \mathrm{Cl}(5 \mathrm{~mL})$ and warmed to r.t. After $10 \mathrm{~min}$, the solution was extracted with $\mathrm{Et}_{2} \mathrm{O}(3 \mathrm{X} 10 \mathrm{~mL})$. The dried $\left(\mathrm{MgSO}_{4}\right)$ extract was concentrated in vacuo and purified by chromatography over silica gel, eluting with 10-15\% EtOAc / hexanes, to give 28 and $29\left(\mathrm{dr}=4: 1\right.$ by ${ }^{1} \mathrm{H}$ NMR). Individual pure fractions of $\mathbf{2 8}(130 \mathrm{mg}, 0.23 \mathrm{mmol}, 53 \%)$ was isolated as a white solid and $\mathbf{2 9}$ (36 mg, 0.064 mmol, 15\%). 28: $[\alpha]_{\mathrm{D}}^{23}+122.9^{\circ}$ (c 0.7); IR 3446, 3029, 2958, 2931, 2875, 1707, 1496, 1455, 1387, 1324, 1197, 1086, $746 \mathrm{~cm}^{-1}$; ${ }^{1} \mathrm{H}$ NMR $(400 \mathrm{MHz}) \delta 7.21-7.35(\mathrm{~m}, 10 \mathrm{H}), 6.35(\mathrm{~d}, \mathrm{~J}=8.8 \mathrm{~Hz}, 1 \mathrm{H})$, $4.73(\mathrm{~d}, \mathrm{~J}=11.6 \mathrm{~Hz}, 1 \mathrm{H}), 4.58-4.59(\mathrm{~m}, 1 \mathrm{H}), 4.48(\mathrm{~d}, \mathrm{~J}=11.6 \mathrm{~Hz}, 1 \mathrm{H}), 4.25(\mathrm{dd}, \mathrm{J}=2.4,9.2 \mathrm{~Hz}, 1 \mathrm{H}), 3.99-$ $4.07(\mathrm{~m}, 2 \mathrm{H}), 3.79-3.85(\mathrm{~m}, 1 \mathrm{H}), 3.38(\mathrm{~d}, \mathrm{~J}=10.4 \mathrm{~Hz}, 1 \mathrm{H}), 3.22(\mathrm{dd}, \mathrm{J}=3.6,13.6 \mathrm{~Hz}, 1 \mathrm{H}), 2.73(\mathrm{dd}, \mathrm{J}=$ 9.6, 13.6 Hz, 1H), 2.16-2.21 (m, 1H), 1.72-1.75 (m, 1H), 1.60-1.63 (m, 1H), $1.25(\mathrm{~d}, \mathrm{~J}=6 \mathrm{~Hz}, 3 \mathrm{H}), 1.13(\mathrm{~d}$, $\mathrm{J}=6.8 \mathrm{~Hz}, 3 \mathrm{H}), 1.01(\mathrm{t}, \mathrm{J}=8.4 \mathrm{~Hz}, 9 \mathrm{H}), 0.66(\mathrm{q}, \mathrm{J}=8.4 \mathrm{~Hz}, 6 \mathrm{H}) ;{ }^{13} \mathrm{C} \mathrm{NMR}(100 \mathrm{MHz}) \delta 186.6,175.1$, 137.4, 135.5, 129.9, 129.7, 129.4, 128.72, 128.67, 127.8, 79.2, 76.4, 73.8, 71.1, 67.5, 60.6, 41.0, 37.6, 33.3, 23.9, 17.6, 7.3, 5.4; HRMS (FAB+) calcd. for $\mathrm{C}_{31} \mathrm{H}_{46} \mathrm{NO}_{5} \mathrm{SSi}(\mathrm{M}+1)$ 572.2866, found 572.2864.

29: $[\alpha]_{\mathrm{D}}^{23}+38.4^{\circ}$ (c 1.25); IR 3484, 2958, 2908, 2874, 1705, 1454, 1364, 1322, 1196, $741 \mathrm{~cm}^{-1} ;{ }^{1} \mathrm{H}$ NMR (300 MHz) d 7.17-7.43 (m, 10H), $6.55(\mathrm{~d}, \mathrm{~J}=9.2 \mathrm{~Hz}, 1 \mathrm{H}), 4.84-4.87(\mathrm{~m}, 1 \mathrm{H}), 4.62-4.67(\mathrm{~m}, 2 \mathrm{H})$, 4.26-4.34 (m, 2H), $3.98(\mathrm{dt}, \mathrm{J}=6.0,17.6 \mathrm{~Hz}, 1 \mathrm{H}), 3.84-3.89(\mathrm{~m}, 1 \mathrm{H}), 3.20(\mathrm{dd}, \mathrm{J}=3.3,13.2 \mathrm{~Hz}, 1 \mathrm{H}), 2.74$ $(\mathrm{d}, \mathrm{J}=7.8 \mathrm{~Hz}, 1 \mathrm{H}), 2.65(\mathrm{dd}, \mathrm{J}=10.5,13.2 \mathrm{~Hz}, 1 \mathrm{H}), 2.16-2.20(\mathrm{~m}, 1 \mathrm{H}), 1.57-1.65(\mathrm{~m}, 1 \mathrm{H}), 1.45-1.52(\mathrm{~m}$, $1 \mathrm{H}), 1.17(\mathrm{~d}, \mathrm{~J}=6.3 \mathrm{~Hz}, 3 \mathrm{H}), 0.93(\mathrm{t}, \mathrm{J}=8.1 \mathrm{~Hz}, 9 \mathrm{H}), 0.87(\mathrm{~d}, \mathrm{~J}=6.9 \mathrm{~Hz}, 3 \mathrm{H}), 0.58(\mathrm{q}, \mathrm{J}=7.8 \mathrm{~Hz}, 6 \mathrm{H}) ;{ }^{13} \mathrm{C}$ NMR $(100 \mathrm{MHz}) \delta 187.1,176.0,137.7,135.7,129.8,129.4,129.1,128.8,128.5,127.8,77.8,76.2,73.2$, 71.3, 67.2, 61.3, 43.8, 38.3, 31.6, 24.0, 13.4, 7.3, 5.4; HRMS (FAB+) calcd. for $\mathrm{C}_{31} \mathrm{H}_{46} \mathrm{NO}_{5} \mathrm{SSi}(\mathrm{M}+1)$ 572.2866, found 572.2868.

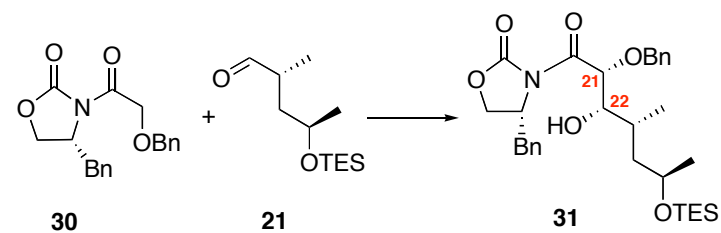

Aldol Adduct 31: To a solution of $\mathbf{3 0}^{4}(49 \mathrm{mg}, 0.15 \mathrm{mmol})$ in $\mathrm{PhMe}(0.35 \mathrm{~mL})$ at $-50^{\circ} \mathrm{C}$ was added $\mathrm{Et}_{3} \mathrm{~N}(24 \mu \mathrm{L}, 0.17 \mathrm{mmol})$ and $\mathrm{Bu}_{2} \mathrm{BOTf}(40 \mu \mathrm{L}, 0.16 \mathrm{mmol})$ via syringe. After $1.5 \mathrm{~h}$, a solution of aldehyde 21 (23 mg, $0.1 \mathrm{mmol})$ in $\mathrm{PhMe}(0.15 \mathrm{~mL})$ was transferred dropwise into the reaction via cannula. After $40 \mathrm{~min}$, the reaction was allowed to warm up to $-30^{\circ} \mathrm{C}$ within $30 \mathrm{~min}$. After $1 \mathrm{~h}$, the reaction was quenched by adding $\mathrm{pH} 7$ phosphate buffer $(0.5 \mathrm{~mL})$ followed by $0.5 \mathrm{~mL}$ of $\mathrm{MeOH}$ and $0.5 \mathrm{~mL}$ of THF. Then, the solution was warmed up to $0^{\circ} \mathrm{C}$. After $5 \mathrm{~min}, 30 \%$ aqueous $\mathrm{H}_{2} \mathrm{O}_{2}(0.5 \mathrm{~mL})$ in $\mathrm{MeOH}(0.5 \mathrm{~mL})$ was added dropwise. After $1 \mathrm{~h}$, the reaction mixture was extracted with EtOAc $(3 \mathrm{X} 15 \mathrm{~mL})$ and the combined organic layer was diluted with $\mathrm{pH} 7$ phosphate buffer $(20 \mathrm{~mL})$ and the mixture was concentrated in vacuo. The resulted mixture was extracted again with $\mathrm{Et}_{2} \mathrm{O}(3 \mathrm{X} 10 \mathrm{~mL})$. The dried $\left(\mathrm{MgSO}_{4}\right)$ extract was concentrated in vacuo and purified by chromatography over silica gel, eluting with 15-20\% EtOAc / hexanes, to give 31 (40 mg, $0.072 \mathrm{mmol}, 72 \%$, contaminated with a small amount (5\%) of the presumed alternate $s y n$ adduct) as a colorless oil: $[\alpha]_{\mathrm{D}}^{23}-1.8^{\circ}$ (c 2.34); IR 3546 (br), 3029, 2957, 2875, 1782, 1709, 
1455, 1357, 1210, 1110, 1051, 1012, 736, $699 \mathrm{~cm}^{-1} ;{ }^{1} \mathrm{H}$ NMR $(300 \mathrm{MHz}) \delta 7.21-7.34(\mathrm{~m}, 10 \mathrm{H}), 5.36(\mathrm{~d}, \mathrm{~J}=$ $2.1 \mathrm{~Hz}, 1 \mathrm{H}), 4.65-4.72(\mathrm{~m}, 2 \mathrm{H}), 4.51(\mathrm{~d}, \mathrm{~J}=11.1 \mathrm{~Hz}, 1 \mathrm{H}), 4.17-4.27(\mathrm{~m}, 2 \mathrm{H}), 3.84-3.90(\mathrm{~m}, 1 \mathrm{H}), 3.59-3.63$ $(\mathrm{m}, 1 \mathrm{H}), 3.32(\mathrm{dd}, \mathrm{J}=3.0,13.2 \mathrm{~Hz}, 1 \mathrm{H}), 2.77(\mathrm{dd}, \mathrm{J}=3.9,13.5 \mathrm{~Hz}, 1 \mathrm{H}), 2.31(\mathrm{~d}, \mathrm{~J}=9.0 \mathrm{~Hz}, 1 \mathrm{H}), 1.74-$ $1.81(\mathrm{~m}, 1 \mathrm{H}), 1.54-1.62(\mathrm{~m}, 1 \mathrm{H}), 1.37-1.47(\mathrm{~m}, 1 \mathrm{H}), 1.12(\mathrm{~d}, \mathrm{~J}=6.0 \mathrm{~Hz}, 3 \mathrm{H}), 1.00(\mathrm{~d}, \mathrm{~J}=6.6 \mathrm{~Hz}, 3 \mathrm{H})$, $0.953(\mathrm{t}, \mathrm{J}=8.1 \mathrm{~Hz}, 9 \mathrm{H}), 0.59$ (q, J = 8.1 Hz, 6H); ${ }^{13} \mathrm{C} \mathrm{NMR}(75 \mathrm{MHz}) \delta 171.5,153.6,137.5,135.6,129.9$, 129.4, 128.9 (2 C's), 128.6, 127.9, 78.8, 76.6, 73.3, 67.4 (2 C's), 56.2, 43.1, 38.2, 34.7, 23.6, 16.2, 7.3, 5.3; HRMS (FAB+) calcd. for $\mathrm{C}_{31} \mathrm{H}_{46} \mathrm{NO}_{6} \mathrm{Si}(\mathrm{M}+1)$ 556.3095, found 556.3094.

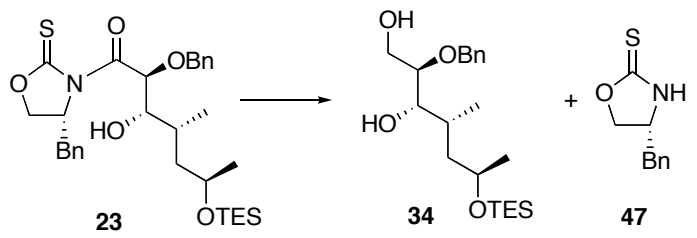

Diol 34: To a solution of $23(17.6 \mathrm{mg}, 0.031 \mathrm{mmol})$ in $\mathrm{THF}(0.16 \mathrm{~mL})$ at $0^{\circ} \mathrm{C}$ added $\mathrm{MeOH}(0.002$ $\mathrm{mL}, 0.037 \mathrm{mmol})$ and $\mathrm{LiBH}_{4}(20 \mu \mathrm{L}, 0.04 \mathrm{mmol}, 2.0 \mathrm{M}$ in THF). After $30 \mathrm{~min}$, the reaction was warmed to r.t. After $30 \mathrm{~min}$, the reaction was quenched with sat. aq. sodium tartarate $(2 \mathrm{~mL})$, after stirring for $10 \mathrm{~min}$, the mixture was extracted with $\mathrm{Et}_{2} \mathrm{O}(3 \mathrm{X} 10 \mathrm{~mL})$. The dried $\left(\mathrm{MgSO}_{4}\right)$ extract was concentrated in vacuo and purified by chromatography over silica gel, eluting carefully with 10-15\% EtOAc / hexanes, to give 34 $(10.6 \mathrm{mg}, 90 \%)$ as a colorless oil: $[\alpha]_{\mathrm{D}}{ }^{23}-14.0^{\circ}$ (c 0.30$)$; IR $3400,2958,2910,2876,1456,1376,1237$, 1160, 1050, 1028, $743 \mathrm{~cm}^{-1} ;{ }^{1} \mathrm{H}$ NMR $(300 \mathrm{MHz}) \delta 7.29-7.35(\mathrm{~m}, 5 \mathrm{H}), 4.66(\mathrm{~d}, \mathrm{~J}=11.4 \mathrm{~Hz}, 1 \mathrm{H}), 4.55(\mathrm{~d}, \mathrm{~J}$ $=11.4 \mathrm{~Hz}, 1 \mathrm{H}), 3.98(\mathrm{dt}, \mathrm{J}=6.0,12.0 \mathrm{~Hz}, 1 \mathrm{H}), 3.77-3.85(\mathrm{~m}, 3 \mathrm{H}), 3.46-3.51(\mathrm{~m}, 1 \mathrm{H}), 3.09(\mathrm{bs}, 1 \mathrm{H}), 2.59$ (bs, 1H), 1.99-2.03 (m, 1H), 1.55-1.62 (m, 1H), 1.43-1.54 (m, 1H), $1.18(\mathrm{~d}, \mathrm{~J}=6.0 \mathrm{~Hz}, 3 \mathrm{H}), 0.95(\mathrm{t}, \mathrm{J}=8.1$ $\mathrm{Hz}, 9 \mathrm{H}), 0.88(\mathrm{~d}, \mathrm{~J}=6.9 \mathrm{~Hz}, 3 \mathrm{H}), 0.61(\mathrm{q}, \mathrm{J}=7.5 \mathrm{~Hz}, 6 \mathrm{H}) ;{ }^{13} \mathrm{C} \mathrm{NMR}(100 \mathrm{MHz}) \delta 138.4,128.9,128.4$, 128.3, 79.0, 75.7, 72.3, 67.2, 62.5, 43.7, 31.6, 23.6, 14.0, 7.3, 5.4; HRMS (FAB+) calcd. for $\mathrm{C}_{21} \mathrm{H}_{39} \mathrm{O}_{4} \mathrm{Si}$ (M+1) 383.2618, found 383.2607.

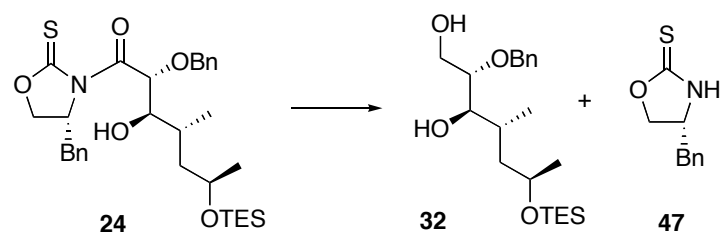

Diol 32: To a solution of $24(15 \mathrm{mg}, 0.026 \mathrm{mmol})$ in THF $(0.15 \mathrm{~mL})$ at $0^{\circ} \mathrm{C}$ added $\mathrm{MeOH}(2 \mu \mathrm{L}$, $0.032 \mathrm{mmol})$ and $\mathrm{LiBH}_{4}(16 \mu \mathrm{L}, 0.032 \mathrm{mmol}, 2.0 \mathrm{M}$ in THF). After $30 \mathrm{~min}$, the reaction was warmed to r.t. After $30 \mathrm{~min}$, the reaction was quenched with sat. aq. sodium tartarate $(2 \mathrm{~mL})$. After $10 \mathrm{~min}$, the mixture was extracted with $\mathrm{Et}_{2} \mathrm{O}(3 \mathrm{X} 10 \mathrm{~mL})$. The dried $\left(\mathrm{MgSO}_{4}\right)$ extract was concentrated in vacuo and purified by chromatography over silica gel, eluting carefully with 10-15\% EtOAc / hexanes, to give 32 (8.6 mg, $89 \%$ ) as a colorless oil: $[\alpha]_{\mathrm{D}}^{23}-5.0^{\circ}$ (c 0.04); IR 3409, 2956, 2917, 2849, 1472, 1456, 1237, 1068, 1050, 1012, $742 \mathrm{~cm}^{-1}$; ${ }^{1} \mathrm{H}$ NMR $(300 \mathrm{MHz}) \delta 7.29-7.36(\mathrm{~m}, 5 \mathrm{H}), 4.62(\mathrm{dd}, \mathrm{J}=3.0,11.7 \mathrm{~Hz}, 1 \mathrm{H}), 4.02(\mathrm{dt}, \mathrm{J}=5.7$, $11.4 \mathrm{~Hz}, 1 \mathrm{H}), 3.84-3.87(\mathrm{~m}, 2 \mathrm{H}), 3.59-3.63(\mathrm{~m}, 1 \mathrm{H}), 3.51(\mathrm{dd}, \mathrm{J}=4.5,9.6 \mathrm{~Hz}, 1 \mathrm{H}), 2.64(\mathrm{bs}, 1 \mathrm{H}), 1.82-1.92$ $(\mathrm{m}, 1 \mathrm{H}), 1.51-1.68(\mathrm{~m}, 2 \mathrm{H}), 1.17(\mathrm{~d}, \mathrm{~J}=6.0 \mathrm{~Hz}, 3 \mathrm{H}), 0.94-0.99(\mathrm{~m}, 12 \mathrm{H}), 0.62(\mathrm{q}, \mathrm{J}=8.1 \mathrm{~Hz}, 6 \mathrm{H}) ;{ }^{13} \mathrm{C}$ NMR (75 MHz) $\delta 138.5,128.9,128.3$ (2 C's), 79.9, 77.6, 71.9, 67.3, 61.7, 42.9, 33.0, 23.9, 17.7, 7.2, 5.3; HRMS (FAB+) calcd. for $\mathrm{C}_{21} \mathrm{H}_{39} \mathrm{O}_{4} \mathrm{Si}(\mathrm{M}+1) 383.2618$, found 383.2624. 


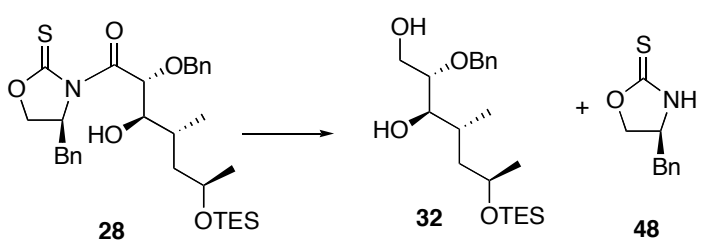

Diol 32: To a solution of $28(10.6 \mathrm{mg}, 0.020 \mathrm{mmol})$ in $\mathrm{THF}(0.15 \mathrm{~mL})$ at $0^{\circ} \mathrm{C}$ added $\mathrm{MeOH}(0.001$ $\mathrm{mL}, 0.022 \mathrm{mmol})$ and $\mathrm{LiBH}_{4}(11 \mu \mathrm{L}, 0.022 \mathrm{mmol}, 2.0 \mathrm{M}$ in THF). After $30 \mathrm{~min}$, the reaction was warmed to r.t. After $30 \mathrm{~min}$, the reaction was quenched with sat. aq. sodium tartarate $(2 \mathrm{~mL})$. After 10 min, the mixture was extracted with $\mathrm{Et}_{2} \mathrm{O}(3 \mathrm{X} 10 \mathrm{~mL})$. The dried $\left(\mathrm{MgSO}_{4}\right)$ extract was concentrated in vacuo and purified by chromatography over silica gel, eluting carefully with 10-15\% EtOAc / hexanes, to give the identical diol $32(6.6 \mathrm{mg}, 86 \%)$ as a colorless oil.

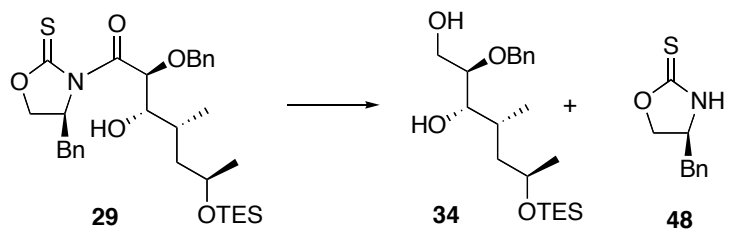

Diol 34: To a solution of 29 (37 mg, $0.065 \mathrm{mmol})$ in THF $(0.32 \mathrm{~mL})$ at $0^{\circ} \mathrm{C}$ added $\mathrm{MeOH}(0.003$ $\mathrm{mL}, 0.078 \mathrm{mmol})$ and $\mathrm{LiBH}_{4}(40 \mu \mathrm{L}, 0.08 \mathrm{mmol}, 2.0 \mathrm{M}$ in THF). After $30 \mathrm{~min}$, the reaction was warmed to r.t. After $30 \mathrm{~min}$, the reaction was quenched with sat. aq. sodium tartarate $(2 \mathrm{~mL})$. After 10 min, the mixture was extracted with $\mathrm{Et}_{2} \mathrm{O}(3 \mathrm{X} 10 \mathrm{~mL})$. The dried $\left(\mathrm{MgSO}_{4}\right)$ extract was concentrated in vacuo and purified by chromatography over silica gel, eluting carefully with 10-15\% EtOAc / hexanes, to give the identical diol 34 (22.0 mg, 92\%) as a colorless oil.

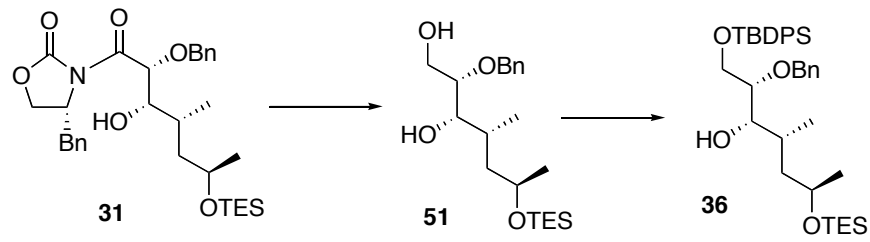

Diol 51: To a solution of $31(21 \mathrm{mg}, 0.037 \mathrm{mmol})$ in $\mathrm{THF}(0.2 \mathrm{~mL})$ at $0^{\circ} \mathrm{C}$ added $\mathrm{MeOH}(0.002$ $\mathrm{mL}, 0.044 \mathrm{mmol})$ and $\mathrm{LiBH}_{4}(22 \mu \mathrm{L}, 0.044 \mathrm{mmol})$. After $2 \mathrm{hr}$, the reaction was quenched with sat. aq. sodium tartarate $(2 \mathrm{~mL})$. After $10 \mathrm{~min}$, the mixture was extracted with $\mathrm{Et}_{2} \mathrm{O}(3 \mathrm{X} 10 \mathrm{~mL})$. The dried $\left(\mathrm{MgSO}_{4}\right)$ extract was concentrated in vacuo. Without further purification, the crude $51(0.037 \mathrm{mmol})$ contaminated with the oxazolidinone was applied directly to the next step.

Silyl ether 36: To a solution of crude $51(0.037 \mathrm{mmol})$ in $\mathrm{CH}_{2} \mathrm{Cl}_{2}(0.2 \mathrm{~mL})$ at $0^{\circ} \mathrm{C}$ added imidazole (3.0 mg, $0.044 \mathrm{mmol}$ ), DMAP (2.1 mg, $0.011 \mathrm{mmol})$ and TBDPSCl (0.014 mL, $0.044 \mathrm{mmol})$. After 20 min, the reaction was quenched with sat. aq. $\mathrm{NH}_{4} \mathrm{Cl}$ and extracted with $\mathrm{Et}_{2} \mathrm{O}(3 \mathrm{X} 10 \mathrm{~mL})$. The dried $\left(\mathrm{MgSO}_{4}\right)$ extract was concentrated in vacuo and purified by chromatography over silica gel, eluting carefully with $2-4 \%$ EtOAc / hexanes, to give $36\left(18 \mathrm{mg}, 78 \%\right.$ over 2 steps) as a colorless oil: $[\alpha]_{\mathrm{D}}{ }^{23}+20.0^{\circ}$ (c 1.16); IR 3445, 3070, 2957, 2931, 2875, 1471, 1456, 1427, 1113, 1059, 739, $701 \mathrm{~cm}^{-1}$; ${ }^{1} \mathrm{H} \mathrm{NMR}(400$ $\mathrm{MHz}) \delta 7.29-7.76(\mathrm{~m}, 15 \mathrm{H}), 4.79(\mathrm{~d}, \mathrm{~J}=11.2 \mathrm{~Hz}, 1 \mathrm{H}), 4.51(\mathrm{~d}, \mathrm{~J}=11.2 \mathrm{~Hz}, 1 \mathrm{H}), 3.84-3.94(\mathrm{~m}, 3 \mathrm{H}), 3.61$ $(\mathrm{dd}, \mathrm{J}=4.8,10.0 \mathrm{~Hz}, 1 \mathrm{H}), 3.49-3.53(\mathrm{~m}, 1 \mathrm{H}), 2.51(\mathrm{~d}, \mathrm{~J}=5.2 \mathrm{~Hz}, 1 \mathrm{H}), 1.68-1.75(\mathrm{~m}, 1 \mathrm{H}), 1.54-1.59(\mathrm{~m}$, $1 \mathrm{H}), 1.43-1.48(\mathrm{~m}, 1 \mathrm{H}), 1.15(\mathrm{~d}, \mathrm{~J}=6.0 \mathrm{~Hz}, 1 \mathrm{H}), 1.11(\mathrm{~s}, 9 \mathrm{H}), 0.91-0.98(\mathrm{~m}, 12 \mathrm{H}), 0.60(\mathrm{q}, \mathrm{J}=7.2 \mathrm{~Hz}$, $3 \mathrm{H}) ;{ }^{13} \mathrm{C}$ NMR (100 MHz) $\delta 138.7,136.1,135.6,135.2,133.7,133.5,130.2,130.0,128.8,128.7,128.25$, 128.20, 80.9, 74.7, 73.5, 67.1, 64.6, 44.4, 32.8, 27.3, 24.0, 19.6, 14.9, 7.3, 5.4; HRMS (FAB+) calcd. for $\mathrm{C}_{37} \mathrm{H}_{57} \mathrm{O}_{4} \mathrm{Si}_{2}(\mathrm{M}+1) 621.3795$, found 621.3799 . 


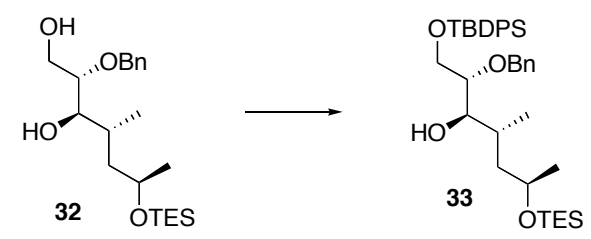

Silyl Ether 33: To a solution of $32(14 \mathrm{mg}, 0.037 \mathrm{mmol})$ in $\mathrm{CH}_{2} \mathrm{Cl}_{2}(0.2 \mathrm{~mL})$ at $0^{\circ} \mathrm{C}$ added imidazole ( $3 \mathrm{mg}, 0.044 \mathrm{mmol})$, DMAP ( $2 \mathrm{mg}, 0.011 \mathrm{mmol})$ and TBDPSCl (0.014 mL, $0.044 \mathrm{mmol})$. After $20 \mathrm{~min}$, the reaction was quenched with sat. aq. $\mathrm{NH}_{4} \mathrm{Cl}$ and extracted with $\mathrm{Et}_{2} \mathrm{O}(3 \times 10 \mathrm{~mL})$. The dried $\left(\mathrm{MgSO}_{4}\right)$ extract was concentrated in vacuo and purified by chromatography over silica gel, eluting carefully with 2-4\% EtOAc / hexanes, to give $\mathbf{3 3}(20 \mathrm{mg}, 87 \%)$ as a colorless oil: $[\alpha]_{\mathrm{D}}{ }^{23}+9.3^{\circ}$ (c 1.30); IR 3440, 3070, 2957, 2931, 2876, 1547, 1471, 1427, 1113, 1069, 739, $701 \mathrm{~cm}^{-1} ;{ }^{1} \mathrm{H}$ NMR (400 MHz)

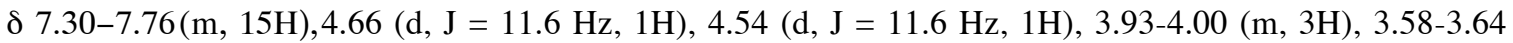
$(\mathrm{m}, 2 \mathrm{H}), 3.05(\mathrm{~d}, \mathrm{~J}=3.6 \mathrm{~Hz}, 1 \mathrm{H}), 1.78-1.85(\mathrm{~m}, 1 \mathrm{H}), 1.63-1.70(\mathrm{~m}, 1 \mathrm{H}), 1.47-1.52(\mathrm{~m}, 1 \mathrm{H}), 1.13(\mathrm{~d}, \mathrm{~J}=5.6$ $\mathrm{Hz}, 3 \mathrm{H}), 1.10(\mathrm{~s}, 9 \mathrm{H}), 0.98(\mathrm{t}, \mathrm{J}=8.0 \mathrm{~Hz}, 9 \mathrm{H}), 0.93(\mathrm{~d}, \mathrm{~J}=6.8 \mathrm{~Hz}, 3 \mathrm{H}), 0.62(\mathrm{q}, \mathrm{J}=7.6 \mathrm{~Hz}, 6 \mathrm{H}) ;{ }^{13} \mathrm{C} \mathrm{NMR}$ $(100 \mathrm{MHz}) \delta 138.9,136.1,135.6,135.2,133.57,133.53,130.2,130.1,128.7,128.20,128.15,127.9,80.4$, 77.2, 72.6, 67.7, 64.5, 42.2, 32.6, 27.3, 24.0, 19.6, 17.5, 7.3, 5.4; HRMS (FAB+) calcd. for $\mathrm{C}_{37} \mathrm{H}_{57} \mathrm{O}_{4} \mathrm{Si}_{2}$ $(\mathrm{M}+1) 621.3795$, found 621.3794 .

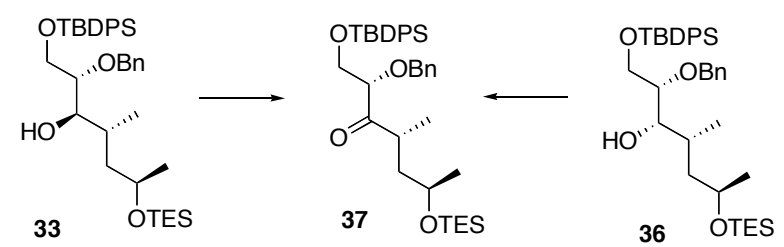

Ketone 37 from 33: To a solution of $\mathbf{3 3}(5.2 \mathrm{mg}, 0.008 \mathrm{mmol})$ in $\mathrm{CH}_{2} \mathrm{Cl}_{2}(0.2 \mathrm{~mL})$ added TPAP $(4.0 \mathrm{mg}, 0.009 \mathrm{mmol})$. After $20 \mathrm{~min}$, the reaction mixture was filtrated through a plug of silica gel eluted with $20 \%$ EtOAc / hexanes $(50 \mathrm{~mL})$. The solution was concentrated in vacuo to give the previously described ketone 37 (3.8 mg, $0.006 \mathrm{mmol}, 73 \%$ ) as a colorless oil: $[\alpha]_{\mathrm{D}}{ }^{23}-11.6^{\circ}$ (c 0.88); IR 3445, 3070, 2957, 2931, 2875, 1471, 1456, 1427, 1113, 1059, 739, $701 \mathrm{~cm}^{-1} ;{ }^{1} \mathrm{H}$ NMR (400 MHz) ठ 7.18-7.71 (m, 15H), $4.72(\mathrm{~d}, \mathrm{~J}=11.6 \mathrm{~Hz}, 1 \mathrm{H}), 4.64(\mathrm{~d}, \mathrm{~J}=12.0 \mathrm{~Hz}, 1 \mathrm{H}), 4.09(\mathrm{t}, \mathrm{J}=4.0 \mathrm{~Hz}, 1 \mathrm{H}), 3.97-$ $4.00(\mathrm{~m}, 2 \mathrm{H}), 3.85(\mathrm{dt}, \mathrm{J}=6.0,12.0 \mathrm{~Hz}, 1 \mathrm{H}), 3.17-3.22(\mathrm{dt}, \mathrm{J}=7.2,13.6 \mathrm{~Hz}, 1 \mathrm{H}), 1.87-1.92(\mathrm{~m}, 1 \mathrm{H}), 1.42-$ $1.47(\mathrm{~m}, 1 \mathrm{H}), 1.12(\mathrm{~d}, \mathrm{~J}=6.0 \mathrm{~Hz}, 3 \mathrm{H}), 1.11(\mathrm{~d}, \mathrm{~J}=6.8 \mathrm{~Hz}, 1 \mathrm{H}), 1.07(\mathrm{~s}, 9 \mathrm{H}), 0.94(\mathrm{t}, \mathrm{J}=8.0 \mathrm{~Hz}, 9 \mathrm{H}), 0.56$ $(\mathrm{q}, \mathrm{J}=8.0 \mathrm{~Hz}, 6 \mathrm{H}) ;{ }^{13} \mathrm{C}$ NMR $(100 \mathrm{MHz}) \delta 213.9,138.4,136.10,136.06,134.8,133.55,133.48,130.5$, $130.4,128.8,128.1,128.0,85.44,73.0,67.3,64.6,42.4,39.0,27.1,24.1,19.6,17.1,7.3,5.3$; HRMS (FAB+) calcd. for $\mathrm{C}_{37} \mathrm{H}_{55} \mathrm{O}_{4} \mathrm{Si}_{2}(\mathrm{M}+1)$ 619.3561, found 619.3593.

Ketone 37 from 36: To a solution of $\mathbf{3 6}$ (4.0 $\mathrm{mg}, 0.006 \mathrm{mmol}$ ) in $\mathrm{CH}_{2} \mathrm{Cl}_{2}$ added TPAP (3.0 mg, $0.008 \mathrm{mmol}$ ). After $20 \mathrm{~min}$, the reaction mixture was filtrated through a plug of silica gel eluted with $20 \%$ EtOAc / hexanes $(50 \mathrm{~mL})$. The solution was concentrated in vacuo to give the identical ketone $\mathbf{3 7}(3.8 \mathrm{mg}$, $0.006 \mathrm{mmol}, 99 \%)$ as a colorless oil.

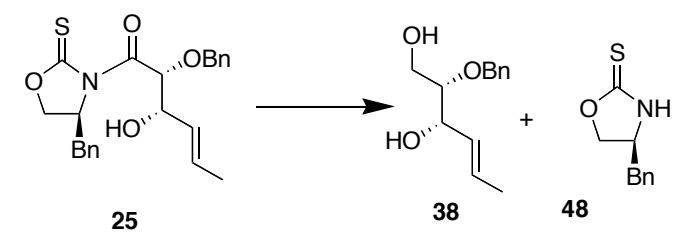

To a solution of $25(15 \mathrm{mg}, 0.036 \mathrm{mmol})$ in THF $(0.2 \mathrm{~mL})$ at $0^{\circ} \mathrm{C}$ added $\mathrm{MeOH}(2 \mu \mathrm{L}, 0.044$ mmol) and $\mathrm{LiBH}_{4}(22 \mu \mathrm{L}, 0.044 \mathrm{mmol}, 2.0 \mathrm{M}$ in THF). After $30 \mathrm{~min}$, the reaction was warmed to r.t. After $30 \mathrm{~min}$, the reaction was quenched with sat. aq. Sodium tartarate $(2 \mathrm{~mL})$, after stirring for $10 \mathrm{~min}$, the mixture was extracted with $\mathrm{Et}_{2} \mathrm{O}(3 \mathrm{X} 10 \mathrm{~mL})$. The dried $\left(\mathrm{MgSO}_{4}\right)$ extract was concentrated in vacuo and purified by chromatography over silica gel, eluting carefully with $10-20 \%$ EtOAc / hexanes, to give 38 (5 $\mathrm{mg}, 63 \%$ ) as a colorless oil. Compound $\mathbf{3 8}$ was identical in all respects with the previously reported 
spectral data $\left({ }^{1} \mathrm{H} \text { NMR, }{ }^{13} \mathrm{C} \text { NMR, }[\alpha]_{\mathrm{D}}\right)^{5}:[\alpha]_{\mathrm{D}}{ }^{23}+17.5^{\circ}(\mathrm{c}, 0.48)$; IR 3394, 3030, 2918, 2854, 1496, 1453, $1207,1089,1064,967,737,680 \mathrm{~cm}^{-1} ;{ }^{1} \mathrm{H}$ NMR $(400 \mathrm{MHz}) \delta$ 7.35-7.43 (m, 5H), 5.83-5.88 (m, 1H), 5.54 (ddd, J = 1.6, 7.2, 15.2 Hz, 1H), $4.73(\mathrm{q}, \mathrm{J}=11.6 \mathrm{~Hz}, 2 \mathrm{H}), 4.23(\mathrm{t}, \mathrm{J}=6.8 \mathrm{~Hz}, 1 \mathrm{H}), 3.84(\mathrm{dd}, \mathrm{J}=4.0,12.0$ $\mathrm{Hz}, 1 \mathrm{H}), 3.68(\mathrm{dd}, \mathrm{J}=4.0,12.0 \mathrm{~Hz}, 1 \mathrm{H}), 3.44-3.48(\mathrm{~m}, 1 \mathrm{H}), 2.47(\mathrm{~s}, \mathrm{br}, 1 \mathrm{H}), 1.93(\mathrm{~s}, \mathrm{br}, 1 \mathrm{H}), 1.76(\mathrm{dd}, \mathrm{J}=$ $0.8,6.4 \mathrm{~Hz}, 3 \mathrm{H}) ;{ }^{13} \mathrm{C}$ NMR $(100 \mathrm{MHz}) \delta 138.3,130.2,130.1,129.1,128.5,128.4,82.7,73.5,73.4,61.9$, 18.3; HRMS (FAB+) calcd. for $\mathrm{C}_{13} \mathrm{H}_{18} \mathrm{O}_{3}(\mathrm{M}+)$ 222.1256, found 222.1258 .

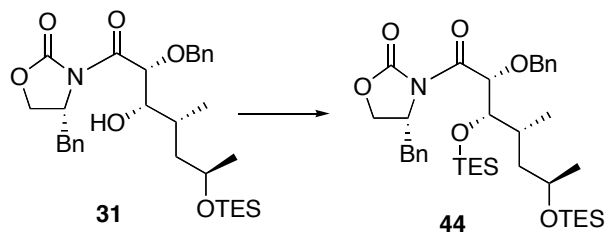

Silyl Ether 44: To a solution of alcohol $31(48 \mathrm{mg}, 0.086 \mathrm{mmol})$ in $\mathrm{CH}_{2} \mathrm{Cl}_{2}(0.22 \mathrm{~mL})$ at $0^{\circ} \mathrm{C}$ added 2,6-lutidine $(0.02 \mathrm{~mL}, 0.17 \mathrm{mmol})$ and TESOTf $(0.03 \mathrm{~mL}, 0.13 \mathrm{mmol})$ via micro-syringe. After $1 \mathrm{~h}$ at $0^{\circ} \mathrm{C}$, the reaction was quenched with sat. aq. $\mathrm{NH}_{4} \mathrm{Cl}(3 \mathrm{~mL})$ and warmed to r.t. After $5 \mathrm{~min}$, the mixture was extract with $\mathrm{Et}_{2} \mathrm{O}(3 \mathrm{X} 10 \mathrm{~mL})$. The dried $\left(\mathrm{MgSO}_{4}\right)$ extract was concentrated in vacuo and purified by chromatography over silica gel, eluting with 4-6\% EtOAc / hexanes, to give 44 (52 $\mathrm{mg}, 0.077 \mathrm{mmol}, 90 \%)$ as a colorless oil: $[\alpha]_{D}^{23}+0.85^{\circ}$ (c 1.18); IR 2956, 2911, 2875, 1785. 1703, 1455, 1380, 1235, 1076, 1010, 735, $698 \mathrm{~cm}^{-1}$; ${ }^{1} \mathrm{H}$ NMR $(300 \mathrm{MHz}) \delta$ 7.16-7.41 (m, 10H), $5.28(\mathrm{~d}, \mathrm{~J}=6.0 \mathrm{~Hz}, 1 \mathrm{H}), 4.71(\mathrm{~d}, \mathrm{~J}=11.7 \mathrm{~Hz}$, $1 \mathrm{H}), 4.60(\mathrm{~d}, \mathrm{~J}=12.0 \mathrm{~Hz}, 2 \mathrm{H}), 4.47-4.49(\mathrm{~m}, 1 \mathrm{H}), 4.00-4.12(\mathrm{~m}, 3 \mathrm{H}), 3.78-3.82(\mathrm{~m}, 1 \mathrm{H}), 3.11(\mathrm{dd}, \mathrm{J}=3.0$, $13.2 \mathrm{~Hz}, 1 \mathrm{H}), 2.41(\mathrm{dd}, \mathrm{J}=3.9,13.5 \mathrm{~Hz}, 1 \mathrm{H}), 1.42-1.56(\mathrm{~m}, 3 \mathrm{H}), 1.10(\mathrm{~d}, \mathrm{~J}=6.0 \mathrm{~Hz}, 3 \mathrm{H}), 0.89-0.97(\mathrm{~m}$, $21 \mathrm{H}), 0.55-0.63(\mathrm{~m}, 12 \mathrm{H}) ;{ }^{13} \mathrm{C}$ NMR $(75 \mathrm{MHz}) \delta 172.1,153.3,138.2 .135 .7,129.8,129.4,128.8,128.6$, $128.2,127.8,79.9,77.3,73.8,67.6,66.8,56.4,44.7,37.7,33.9,24.1,15.2,7.5,7.4,5.8,5.4$; HRMS (FAB+) calcd. for $\mathrm{C}_{37} \mathrm{H}_{60} \mathrm{NO}_{6} \mathrm{Si}_{2}(\mathrm{M}+1) 670.3959$, found 670.3973 .

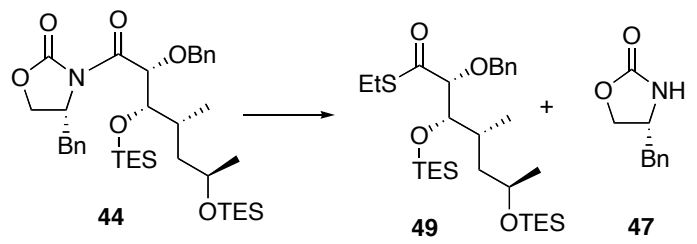

Thioester 49: To a solution of EtSH $(0.014 \mathrm{~mL}, 0.18 \mathrm{mmol})$ in THF $(0.7 \mathrm{~mL})$ was added catalytic amount of $\mathrm{KH}$ ( $30 \mathrm{wt}$. \% in mineral oil). After $30 \mathrm{~min}$, the solution was cooled to $0^{\circ} \mathrm{C}$. A solution of 49 (40 $\mathrm{mg}, 0.06 \mathrm{mmol})$ in THF $(0.3 \mathrm{~mL})$ was transferred via cannula dropwise. After $20 \mathrm{~min}$ at $0^{\circ} \mathrm{C}$, the reaction was warmed to r.t. After $2 \mathrm{~h}$, the reaction was quenched with sat. aq. $\mathrm{NH}_{4} \mathrm{Cl}(3 \mathrm{~mL})$. After $5 \mathrm{~min}$, the mixture was extract with $\mathrm{Et}_{2} \mathrm{O}(3 \times 10 \mathrm{~mL})$. The dried $\left(\mathrm{MgSO}_{4}\right)$ extract was concentrated in vacuo and purified by chromatography over silica gel, eluting with 2-4\% EtOAc / hexanes, to give $\mathbf{4 9}$ (30 mg, 0.054 mmol, 89\%) as a colorless oil: $[\alpha]_{\mathrm{D}}^{23}+65.8^{\circ}$ (c 0.66); IR 2956, 2934, 2876, 1733, 1682, 1456, 1378, 1238, 1123, 1074, 1008, 738, $698 \mathrm{~cm}^{-1}$; ${ }^{1} \mathrm{H}$ NMR (300 MHz) $\delta 7.29-7.43(\mathrm{~m}, 5 \mathrm{H}), 4.67(\mathrm{~d}, \mathrm{~J}=10.8 \mathrm{~Hz}, 1 \mathrm{H}), 4.42$ $(\mathrm{d}, \mathrm{J}=11.1 \mathrm{~Hz}, 1 \mathrm{H}), 3.90(\mathrm{~d}, \mathrm{~J}=6.6 \mathrm{~Hz}, 1 \mathrm{H}), 3.78-3.81(\mathrm{~m}, 2 \mathrm{H}), 2.87(\mathrm{q}, \mathrm{J}=7.5 \mathrm{~Hz}, 2 \mathrm{H}), 1.42-1.52(\mathrm{~m}$, $3 \mathrm{H}), 1.25(\mathrm{t}, \mathrm{J}=7.2 \mathrm{~Hz}, 3 \mathrm{H}), 1.08(\mathrm{~d}, \mathrm{~J}=6.0 \mathrm{~Hz}, 3 \mathrm{H}), 0.79-0.86(\mathrm{~m}, 21 \mathrm{H}), 0.49-0.62(\mathrm{~m}, 12 \mathrm{H}) ;{ }^{13} \mathrm{C}$ NMR (75 MHz) $\delta$ 202.3, 137.7, 128.6, 128.4, 128.1, 88.9, 77.6, 73.4, 67.3, 45.2, 33.1, 23.8, 22.8, 14.9, 14.0, 7.4, 7.3, 5.7, 5.4; HRMS (FAB+) calcd. for $\mathrm{C}_{29} \mathrm{H}_{55} \mathrm{O}_{4} \mathrm{Si}_{2} \mathrm{~S}(\mathrm{M}+1)$ 555.3360, found 555.3367.

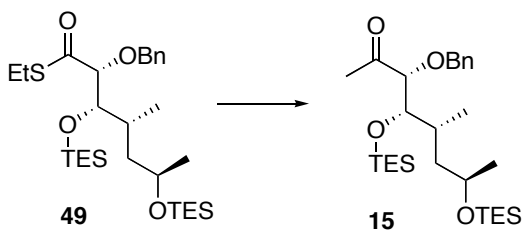

Ketone 15: To a suspension of $\mathrm{CuI}(56 \mathrm{mg}, 0.3 \mathrm{mmol})$ in $\mathrm{Et}_{2} \mathrm{O}(0.5 \mathrm{~mL})$ at $0^{\circ} \mathrm{C}$ was added $\mathrm{MeLi}$ $\left(0.35 \mathrm{~mL}, 0.56 \mathrm{mmol}, 1.6 \mathrm{M}\right.$ in $\left.\mathrm{Et}_{2} \mathrm{O}\right)$. After $15 \mathrm{~min}$, the colorless solution was cooled to $-50^{\circ} \mathrm{C}$ and a 
solution of $49(27 \mathrm{mg}, 0.05 \mathrm{mmol})$ in $\mathrm{Et}_{2} \mathrm{O}(0.3 \mathrm{~mL})$ was transferred into the reaction dropwise via cannula. After $2 \mathrm{hr}$, the reaction was quenched with sat. aq. $\mathrm{NH}_{4} \mathrm{Cl}(3 \mathrm{~mL})$ at $-50^{\circ} \mathrm{C}$, warmed to r.t. and extracted with $\mathrm{Et}_{2} \mathrm{O}(3 \mathrm{X} 10 \mathrm{~mL})$. The dried $\left(\mathrm{MgSO}_{4}\right)$ extract was concentrated in vacuo and purified by chromatography over silica gel, eluting with 2-4\% EtOAc / hexanes, to give 15 (23 mg, $0.046 \mathrm{mmol}, 89 \%$ ) as a colorless oil: $[\alpha]_{\mathrm{D}}{ }^{23}+27.0^{\circ}$ (c 0.30); IR 2956, 2918, 2876, 1734, 1716, 1652, 1456, 1377, 1238, 1079, 1008, 738, $697 \mathrm{~cm}^{-1}$; ${ }_{1} \mathrm{H}$ NMR (400 MHz) $\delta ~ 7.30-7.37(\mathrm{~m}, 5 \mathrm{H}), 4.50(\mathrm{~s}, 2 \mathrm{H}), 3.76-3.85(\mathrm{~m}, 2 \mathrm{H}), 3.76(\mathrm{~d}, \mathrm{~J}=$ $6.4 \mathrm{~Hz}, 1 \mathrm{H}), 2.17(\mathrm{~s}, 3 \mathrm{H}), 1.50-1.52(\mathrm{~m}, 3 \mathrm{H}), 1.13(\mathrm{~d}, \mathrm{~J}=6.0 \mathrm{~Hz}, 3 \mathrm{H}), 0.90-1.00(\mathrm{~m}, 21 \mathrm{H}), 0.57-0.64(\mathrm{~m}$, $12 \mathrm{H}) ;{ }^{13} \mathrm{C}$ NMR $(75 \mathrm{MHz}) \delta 210.9,137.7,128.8,128.4,128.3,89.1,77.4,73.3,67.4,44.9,33.4,27.4,23.8$, 14.3, 7.4, 7.3, 5.7, 5.4; HRMS (FAB+) calcd. for $\mathrm{C}_{28} \mathrm{H}_{53} \mathrm{O}_{4} \mathrm{Si}_{2}(\mathrm{M}+1)$ 509.3482, found 509.3487.

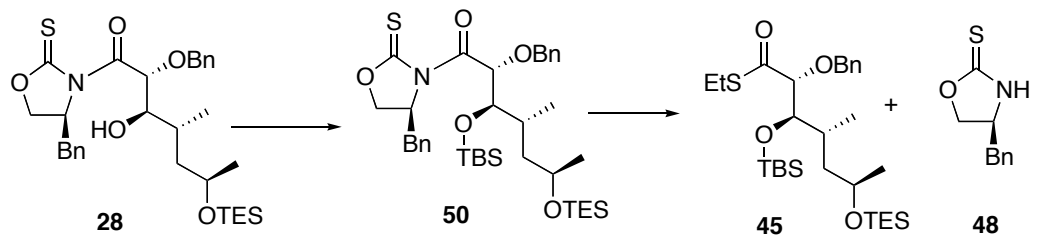

Silyl ether 50: To a solution of alcohol $28(57 \mathrm{mg}, 0.1 \mathrm{mmol})$ in $\mathrm{CH}_{2} \mathrm{Cl}_{2}(0.20 \mathrm{~mL})$ at $0^{\circ} \mathrm{C}$ added 2,6-lutidine $(14 \mu \mathrm{L}, 0.12 \mathrm{mmol})$ and TESOTf $(34 \mu \mathrm{L}, 0.15 \mathrm{mmol})$ via syringe. After $1 \mathrm{~h}$, the reaction was warmed to r.t. and quenched with sat. aq. $\mathrm{NH}_{4} \mathrm{Cl}(3 \mathrm{~mL})$. After $5 \mathrm{~min}$, and the mixture was extracted with $\mathrm{Et}_{2} \mathrm{O}(3 \mathrm{X} 10 \mathrm{~mL})$. The dried $\left(\mathrm{MgSO}_{4}\right)$ extract was concentrated in vacuo and to yield crude $\mathbf{5 0}$ and was applied to the next step without further purification.

Thioester 45: To a solution of EtSH $(0.022 \mathrm{~mL}, 0.30 \mathrm{mmol})$ in THF $(1.2 \mathrm{~mL})$ was added catalytic amount of $\mathrm{KH}$ (30 wt.\% in mineral oil). After $30 \mathrm{~min}$, the solution was cooled to $0^{\circ} \mathrm{C}$ and a solution of crude $50(0.1 \mathrm{mmol})$ in $\mathrm{THF}(0.5 \mathrm{~mL})$ was transferred via cannula dropwise. After $20 \mathrm{~min}$ at $0^{\circ} \mathrm{C}$, the reaction was warmed to r.t. After $2 \mathrm{~h}$, the reaction was quenched with sat. aq. $\mathrm{NH}_{4} \mathrm{Cl}(3 \mathrm{~mL})$. After $5 \mathrm{~min}$, and the mixture was extracted with $\mathrm{Et}_{2} \mathrm{O}(3 \mathrm{X} 10 \mathrm{~mL})$. The dried $\left(\mathrm{MgSO}_{4}\right)$ extract was concentrated in vacuo and purified by chromatography over silica gel, eluting with 2-4\% EtOAc / hexanes, to give 45 (43 $\mathrm{mg}, 0.077 \mathrm{mmol}, 77 \%$ over 2 steps) as a colorless oil: $[\alpha]_{\mathrm{D}}{ }^{23}+36.6^{\circ}$ (c 0.92); IR 2956, 2930, 2876, 1684, 1457, 1376, 1252, 1123, 1078, 1006, 837, 775, 742, $697 \mathrm{~cm}^{-1} ;{ }^{1} \mathrm{H}$ NMR $(300 \mathrm{MHz}) \delta 7.26-7.40$ (m, 5H), $4.69(\mathrm{~d}, \mathrm{~J}=11.4 \mathrm{~Hz}, 1 \mathrm{H}), 4.53(\mathrm{~d}, \mathrm{~J}=11.1 \mathrm{~Hz}, 1 \mathrm{H}), 3.98(\mathrm{~d}, \mathrm{~J}=6.6 \mathrm{~Hz}, 1 \mathrm{H}), 3.79-3.88(\mathrm{~m}, 2 \mathrm{H}), 2.87(\mathrm{q}, \mathrm{J}$ $=7.5 \mathrm{~Hz}, 2 \mathrm{H}), 1.79-1.81(\mathrm{~m}, 1 \mathrm{H}), 1.65-1.70(\mathrm{~m}, 1 \mathrm{H}), 1.31-1.39(\mathrm{~m}, 1 \mathrm{H}), 1.26(\mathrm{t}, \mathrm{J}=7.5 \mathrm{~Hz}, 3 \mathrm{H}), 1.06(\mathrm{~d}, \mathrm{~J}$ $=6.0 \mathrm{~Hz}, 3 \mathrm{H}), 0.86-0.96(\mathrm{~m}, 21 \mathrm{H}), 0.56(\mathrm{q}, \mathrm{J}=7.8 \mathrm{~Hz}, 6 \mathrm{H}), 0.06(\mathrm{~s}, 3 \mathrm{H}), 0.02(\mathrm{~s}, 3 \mathrm{H}) ;{ }^{13} \mathrm{C} \mathrm{NMR}(75 \mathrm{MHz})$

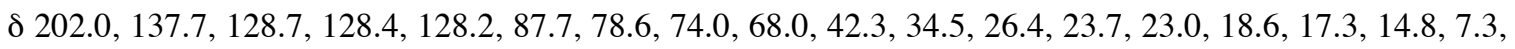
5.4, -3.9, -4.0; HRMS (FAB+) calcd. for $\mathrm{C}_{29} \mathrm{H}_{53} \mathrm{O}_{4} \mathrm{Si}_{2} \mathrm{~S}(\mathrm{M}-1)$ 553.3178, found 553.3159.

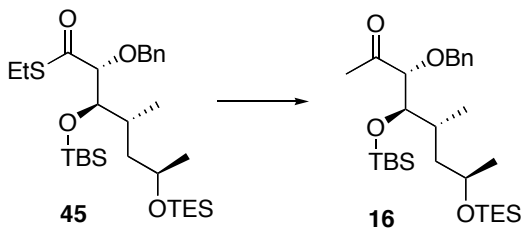

Ketone 16: To a suspension of $\mathrm{CuI}(57 \mathrm{mg}, 0.29 \mathrm{mmol})$ in $\mathrm{Et}_{2} \mathrm{O}(1.5 \mathrm{~mL})$ at $0^{\circ} \mathrm{C}$ added $\mathrm{MeLi}$ $\left(0.37 \mathrm{~mL}, 0.59 \mathrm{mmol}, 1.6 \mathrm{M}\right.$ in $\left.\mathrm{Et}_{2} \mathrm{O}\right)$. After $15 \mathrm{~min}$, the colorless solution was cooled to $-50^{\circ} \mathrm{C}$ and a solution of $45(30 \mathrm{mg}, 0.054 \mathrm{mmol})$ in $\mathrm{Et}_{2} \mathrm{O}(1.1 \mathrm{~mL})$ was transferred into the reaction dropwise via cannula. After $2 \mathrm{~h}$, the reaction was quenched with sat. aq. $\mathrm{NH}_{4} \mathrm{Cl}(3 \mathrm{~mL})$ at $-50^{\circ} \mathrm{C}$, warmed to r.t. and extracted with $\mathrm{Et}_{2} \mathrm{O}(3 \mathrm{X} 10 \mathrm{~mL})$. The dried $\left(\mathrm{MgSO}_{4}\right)$ extract was concentrated in vacuo and purified by chromatography over silica gel, eluting with 2-4\% EtOAc / hexanes, to give 16 (20 mg, $0.040 \mathrm{mmol}, 74 \%)$ as a colorless oil: $[\alpha]_{\mathrm{D}}{ }^{23}+31.0^{\circ}$ (c 0.63); IR 2956, 2930, 2877, 1717, 1457, 1416, 1378, 1253, 1005, 836, 775, $697 \mathrm{~cm}^{-1}$; ${ }^{1} \mathrm{H}$ NMR (400 MHz) $\delta 7.29-7.35$ (m, 5H), 4.48 (s, 2H), 3.80-3.86 (m, 3H), 2.19 (s, 3H), $1.69-1.81(\mathrm{~m}, 1 \mathrm{H}), 1.62-1.65(\mathrm{~m}, 1 \mathrm{H}), 1.31-1.41(\mathrm{~m}, 1 \mathrm{H}), 1.08(\mathrm{~d}, \mathrm{~J}=6.0 \mathrm{~Hz}, 3 \mathrm{H}), 0.87-0.97(\mathrm{~m}, 21 \mathrm{H})$, $0.58(\mathrm{t}, \mathrm{J}=7.8 \mathrm{~Hz}, 6 \mathrm{H}), 0.08(\mathrm{~s}, 3 \mathrm{H}), 0.02(\mathrm{~s}, 3 \mathrm{H}) ;{ }^{13} \mathrm{C} \mathrm{NMR}(75 \mathrm{MHz}) \delta 210.9,137.7,128.8,128.5,128.4$, 
86.4, 78.3, 73.1, 67.8, 42.7, 34.9, 28.4, 26.4, 23.7, 18.6, 16.5, 7.3, 5.4, -3.9, -4.0; HRMS (FAB+) calcd. for $\mathrm{C}_{28} \mathrm{H}_{52} \mathrm{NO}_{4} \mathrm{Si}_{2}(\mathrm{M}+)$ 508.3404, found 508.3366.

(1) D. D. Perrin, W. L. F. Armarego, Purification of Laboratory Chemicals: Third Edition; Pergamon Press: New York, 1993.

(2) Myers, A. G.; McKinstry, L. J. Org. Chem. 1996, 61, 2428-40.

(3) Crimmins, M. T.; McDougall, P. J. Org. Lett. 2003, 5, 591-94.

(4) Evans, D.A.; Gage, J. R.; Leighton, J. L.; Kim, A. S. J. Org. Chem. 1992, 57, 1961-3.

46.

(5) Fuhry, M. A. M.; Holmes, A. B.; Marshall, D. R. J. Chem. Soc., Perkin Trans. 1 1993, $2743-$ 